\title{
THE EFFECT OF SLIGHTLY FASTER STRAIN RATES AND INTERNAL HYDROGEN ON URANIUM-0.8 WEIGHT PERCENT TITANIUM ALLOY MECHANICAL PROPERTIES
}

\author{
E. L. Bird
}

Materials Engineering Department

Development Division

Prepared by the

Oak Ridge Y-12 Plant

P. O. Bcx 2009, Oak Ridge, Tennessee 37831-8169 operated by

MARTIN MARIETTA ENERGY SYSTEMS, INC. for the

U.S. DEPARTMENT OF ENERGY under contract DE-AC05-84OR21400

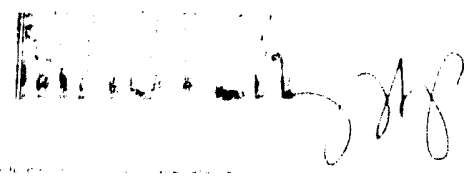




\section{CONTENTS}

SUMMARY $\ldots \ldots \ldots \ldots \ldots \ldots \ldots \ldots \ldots \ldots \ldots \ldots \ldots \ldots \ldots \ldots \ldots$

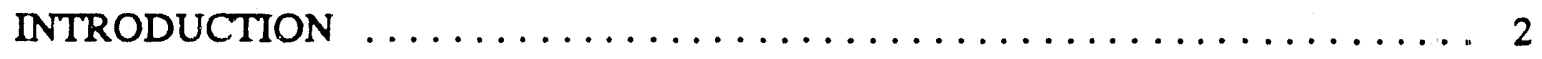

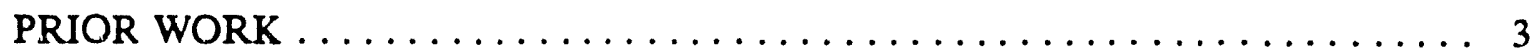

PRESENTATION OF EXPERIMENTAL WORK $\ldots \ldots \ldots \ldots \ldots \ldots \ldots \ldots \ldots$

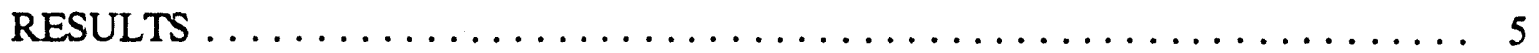

DISCUSSION $\ldots \ldots \ldots \ldots \ldots \ldots \ldots \ldots \ldots \ldots \ldots \ldots \ldots \ldots \ldots \ldots \ldots$

FUTURE WORK $\ldots \ldots \ldots \ldots \ldots \ldots \ldots \ldots \ldots \ldots \ldots \ldots \ldots \ldots \ldots$

ACKNOWLEDGEMENTS $\ldots \ldots \ldots \ldots \ldots \ldots \ldots \ldots \ldots \ldots \ldots \ldots \ldots$

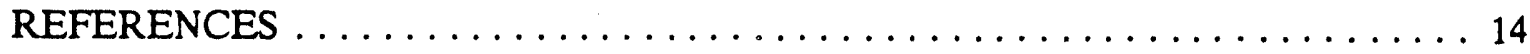




\section{SUMMARY}

Mechanical testing of uranium- 0.8 wt \% titanium (U-0.8 wt \% Ti) alloys can affect the outcome of mechanical properties, primarily ductility, by varying the crosshead velocity, which changes the strain rate. However, most specifications that govern mechanical properties of this alloy reference ASTM E-8, which limits the speed to 0.5 in./in. of gage length per minute. Our current procedure for testing U-0.8Ti is not at the maximum speed permitted in ASTM E-8, so an experiment was designed to evaluate the effect of maximizing the crosshead velocity per ASTM E-8. In order to create a fair assessment, tensile specimens were prepared that were low in internal hydrogen $(0.02 \mathrm{ppm})$ and higher in internal hydrogen $(0.36 \mathrm{ppm})$. External hydrogen effects were minimized by testing in a controlled environment that contained less than $10 \%$ relative humidity. Test results showed that for the low hydrogen test group, increasing the crosshead velocity caused a significant increase in reduction in area (RA), but not in elongation. For the higher hydrogen test group, increasing the speed resulted in a significant increase in RA and an increase, though not statistically significant, in elongation. Of equal importance was an observation that strongly suggests a correlation between material defects, like inclusion clusters, and higher hydrogen content, especially at the slower strain rate that would explain the erratic behavior in ductile properties associated with this alloy. As a result of this study, increasing the crosshead velocity to $0.32 \mathrm{in} . / \mathrm{min}$ is recommended for mechanical testing of U-0.8Ti alloys. 


\section{INTRODUCTION}

The purpose of this study was to evaluate the effect of increasing the crosshead velocity during mechanical testing of the U-0.8Ti alloy. Specification requirements for testing this alloy, typically reference ASTM E-8, which limits the maximum crosshead velocity to 0.5 in./in. of gage length per minute. ${ }^{1}$ For Type T-8 tensile specimens (0.64-in. gage length $x 0.16$ in. gage diam), the current crosshead velocity of $0.15 \mathrm{in} . / \mathrm{min}$ could be increased to $0.32 \mathrm{in} / \mathrm{min}$ and still meet the requirements of ASTM E-8. Jackson has shown that external hydrogen embrittlement can occur during tensile loading of this alloy under certain conditions. ${ }^{2}$ Powell has demonstrated the embrittlement effects of higher internal or bulk hydrogen on U-Ti alloys. $^{3}$ Therefore, an experiment was designed to load U-0.8Ti tensile specimens in a controlled environment with less than $10 \% \mathrm{RH}$ at the maximum allowable speed per ASTM E-8 to see if ductile properties improved. Tensile specimens were prepared that provided an extremely low range of bulk hydrogen $(0.02 \mathrm{ppm})$ and a higher range of bulk hydrogen $(0.36 \mathrm{ppm})$. Internal hydrogen, which is referred to in this report as bulk hydrogen, is absorbed in the molten salt bath during the preheat operation prior to extrusion. 


\section{PRIOR WORK}

Previous efforts designed to evaluate the effects of testing at faster speeds were conducted at a much faster crosshead velocity ( $5.0 \mathrm{in} . / \mathrm{min}$ ), which does not meet ASTM E-8 requirements. These results indicated that testing at that velocity did no: show improvements in total elongation but did show improvements in RA values for extruded rod with low bulk hydrogen $(0.03 \mathrm{ppm})$. 


\section{PRESENTATION OF EXPERIMENTAL WORK}

Two billets from the same ingot were extruded and machined into test components. One of the test components was immersed in the production salt bath for an additional $1 \mathrm{~h}$, tested for hydrogen, and vacuum gamma solution heat treated at $800^{\circ} \mathrm{C}$ for $1 \mathrm{~h}$. The other test component was vacuum gamma solution heat treated at $800^{\circ} \mathrm{C}$ for $8 \mathrm{~h}$. Both test components were immersion quenched in water after heat treating, aged together in argon at $385^{\circ} \mathrm{C}$ for $4.5 \mathrm{~h}$, and quenched.

Two test sections were machined from each component. Each section was then machined into six tensile specimens, hydrogen gas samples, and chemistry samples. Half of the tensile specimens were tested according to the current procedure, which specifies an initial speed of 0.05 -in./min until yield reaches $0.85 \%$ extension under load (EUL), at which time, the speed is increased to $0.15 \mathrm{in} . / \mathrm{min}$. The other half of the tensile bars were pulled at the initial speed of $0.05 \mathrm{in} . / \mathrm{min}$ until yield reached $0.85 \%$ EUL, and then the crosshead velocity was increased to $0.32 \mathrm{in} . / \mathrm{min}$. The approximate strain rates for crosshead speeds of 0.15 and $0.32 \mathrm{in} . / \mathrm{min}$ for the 0.64 -in. gage length were calculated to be 0.0039 and 0.0083 in./in./s, respectively. The test environment was controlled using dried air that contained less than $10 \%$ relative humidity. 


\section{RESULTS}

Internal hydrogen contents are given in Table 1 for each component before and after solution heat treatment. These results reveal that an additional soak of $1 \mathrm{~h}$ in the salt bath $\left(630^{\circ} \mathrm{C}\right)$ increases the internal hydrogen considerably for a 0.5 -in.-thick wall, but heat treating for only $1 \mathrm{~h}$ at $800^{\circ} \mathrm{C}$ in vacuum reduced that amount by almost $50 \%$. The starting bulk hydrogen for component 2 of only $0.11 \mathrm{ppm}$ seems to be low for an extruded billet that was soaked in the salt bath approximately $4 \mathrm{~h}$ prior to extrusion. Chemical analyses are presented in Table 2 for both components.

Table 1. Bulk hydrogen results (ppm)

\begin{tabular}{ccc}
\hline Test component & Before heat treatment & After heat treatment \\
\hline 1 & 0.69 & Section $1-0.37$ \\
& & Section $2-0.35$ \\
2 & 0.11 & Section $1-0.02$ \\
& & Section 2-0.02 \\
\hline
\end{tabular}

NOTE: Test component 1 was given an additional soak in the production salt bath for $1 \mathrm{~h}$ prior to the vacuum solution heat treatment which was $800^{\circ} \mathrm{C}$ for $1 \mathrm{~h}$. Component 2 was solution heat treated at $800^{\circ} \mathrm{C}$ for $8 \mathrm{~h}$.

Table 2 Chemistry results

\begin{tabular}{ccccc}
\hline $\begin{array}{c}\text { Test } \\
\text { component }\end{array}$ & $\begin{array}{c}\text { Titanium } \\
(\mathrm{wt} \%)\end{array}$ & $\begin{array}{c}\text { Carbon } \\
(\mathrm{ppm})\end{array}$ & $\begin{array}{c}\text { Iron } \\
(\mathrm{ppm})\end{array}$ & $\begin{array}{c}\text { Silicon } \\
(\mathrm{ppm})\end{array}$ \\
\hline 1 & 0.799 & 49 & 50 & 40 \\
2 & 0.808 & 38 & 40 & 30 \\
\hline
\end{tabular}

Mechanical properties, which include uniform elongation measurements, are presented in Table 3. Uniform elongation measurements were taken because these values are usually more representative of actual ductility than total elongation. These results indicate that for the low hydrogen test group, testing at the faster rate does show an significant improvement in $R A$ values but not in elongation. Strength values remained equal regardless of speed or hydrogen content. For the higher hydrogen test group, RA values, again, improved significantly while elongation values averaged slightly higher but were not statistically significant. Because of the high variance in ductile properties associated with the group of tensile bars with the higher hydrogen content tested at the current crosshead velocity of $0.15 \mathrm{in} . \mathrm{min}$, these tensile fracture surfaces were examined using the scanning electron microscope (SEM). As noted in Table 3, many of these fractures originated at flaws identified as inclusion clusters, as shown in Fig. 1. The erratic ductile behavior manifested by the tensile specimens with higher hydrogen, that were tested at $0.15 \mathrm{in} . / \mathrm{min}$, prompted 
Table 3. Mechanical properties-hydrogen content vering cromahead velocity

\begin{tabular}{|c|c|c|c|c|c|c|c|}
\hline $\begin{array}{c}\text { Test } \\
\text { component }\end{array}$ & $\begin{array}{l}\text { Section } \\
\text { number }\end{array}$ & $\begin{array}{c}\text { Crosshead } \\
\text { speed } \\
\text { (in./min) }\end{array}$ & $\begin{array}{l}\text { Ultimate } \\
\text { tensile } \\
\text { strength } \\
\text { (ksi) }\end{array}$ & $\begin{array}{c}\text { Yield } \\
\text { strength at } \\
0.85 \text { EUL } \\
\text { (ksi) }\end{array}$ & $\begin{array}{c}\text { Total } \\
\text { elongation } \\
\text { in } 0.64 \text { in. } \\
(\%)\end{array}$ & $\begin{array}{c}\text { Reduction } \\
\text { in area } \\
(\%)\end{array}$ & $\begin{array}{c}\text { Uniform } \\
\text { strain } \\
(\%)\end{array}$ \\
\hline \multirow[t]{3}{*}{1} & 1 & 0.15 & 226.3 & 136.0 & $17.2^{a}$ & 16.8 & 18.8 \\
\hline & & & 222.8 & 138.5 & 17.2 & 20.2 & 16.4 \\
\hline & & & 216.6 & 140.0 & $12.5^{a}$ & 12.1 & 12.2 \\
\hline \multirow[t]{4}{*}{1} & 2 & 0.15 & 221.3 & 140.7 & $10.2^{b}$ & 13.2 & 12.9 \\
\hline & & & 221.8 & 142.9 & 9.4 & 13.2 & 12.7 \\
\hline & & & 223.2 & 140.7 & 17.2 & 16.5 & 17.0 \\
\hline & & & $222.0 \pm 2.9$ & $139.8 \pm 2.1$ & $14.0 \pm 3.4$ & $15.3 \pm 2.8$ & $14.9 \pm 2.6$ \\
\hline \multirow[t]{3}{*}{1} & 1 & 0.32 & 218.6 & 139.5 & 17.2 & 22.2 & 16.4 \\
\hline & & & 218.8 & 136.5 & $18.8^{a}$ & 21.2 & 16.0 \\
\hline & & & 219.8 & 136.7 & 17.2 & 23.4 & 17.2 \\
\hline \multirow[t]{4}{*}{1} & 2 & 0.32 & 221.0 & 140.7 & $17.2^{a}$ & 24.4 & 14.0 \\
\hline & & & 222.3 & 145.4 & $17.2^{a}$ & 22.2 & 16.0 \\
\hline & & & 222.0 & 146.2 & $17.2^{a}$ & 25.6 & 14.8 \\
\hline & & & $220.4 \pm 2.9$ & $140.8 \pm 3.8$ & $17.5 \pm 0.6$ & $23.2 \pm 1.5$ & $15.7 \pm 1.1$ \\
\hline \multirow[t]{3}{*}{2} & 1 & 0.15 & 217.3 & 136.5 & 20.3 & 36.8 & 16.4 \\
\hline & & & 218.6 & 136.3 & 21.9 & 32.8 & 17.6 \\
\hline & & & 223.8 & 141.5 & 23.4 & 34.0 & 18.0 \\
\hline \multirow[t]{4}{*}{2} & 2 & 0.15 & 223.5 & 140.2 & $18.8^{a}$ & 30.7 & 17.2 \\
\hline & & & 217.1 & 140.2 & 20.3 & 34.8 & 17.6 \\
\hline & & & 226.3 & 146.7 & 23.4 & 34.0 & 16.8 \\
\hline & & & $221.0 \pm 3.6$ & $140.2 \pm 3.5$ & $21.4 \pm 1.7$ & $33.9 \pm 1.9$ & $17.3 \pm 0.5$ \\
\hline \multirow[t]{3}{*}{2} & 1 & 0.32 & 218.6 & 132.6 & 20.3 & 36.8 & 18.4 \\
\hline & & & 221.0 & 138.5 & 20.30 & 34.8 & 16.8 \\
\hline & & & 219.1 & 135.8 & 21.9 & 38.8 & 16.8 \\
\hline \multirow[t]{4}{*}{2} & 2 & 0.32 & 223.5 & 140.5 & 20.3 & 40.7 & 16.8 \\
\hline & & & 223.8 & 145.9 & 21.9 & 36.0 & 16.0 \\
\hline & & & 224.8 & 145.5 & 21.9 & 41.9 & 16.0 \\
\hline & & & $221.8 \pm 2.4$ & $139.8 \pm 4.8$ & $21.1 \pm 0.8$ & $38.2 \pm 2.5$ & $16.8 \pm 0.8$ \\
\hline
\end{tabular}

Note: Test Blank $1=0.36$ bulk hydrogen; Test Blank $2=0.02 \mathrm{ppm}$ bulk hydrogen.

$a_{\text {Interior fracture origin at inclusion cluster. }}$

bsurface fracture origin at inclusion cluster. 
(a) Tensile spocimon fracture with origin enclosed.

(b) Closer view of origin. Note brittle, quasi-cleavage facets associated with the fracture surface.

(c) Inctusion cluster at origin of fracture.
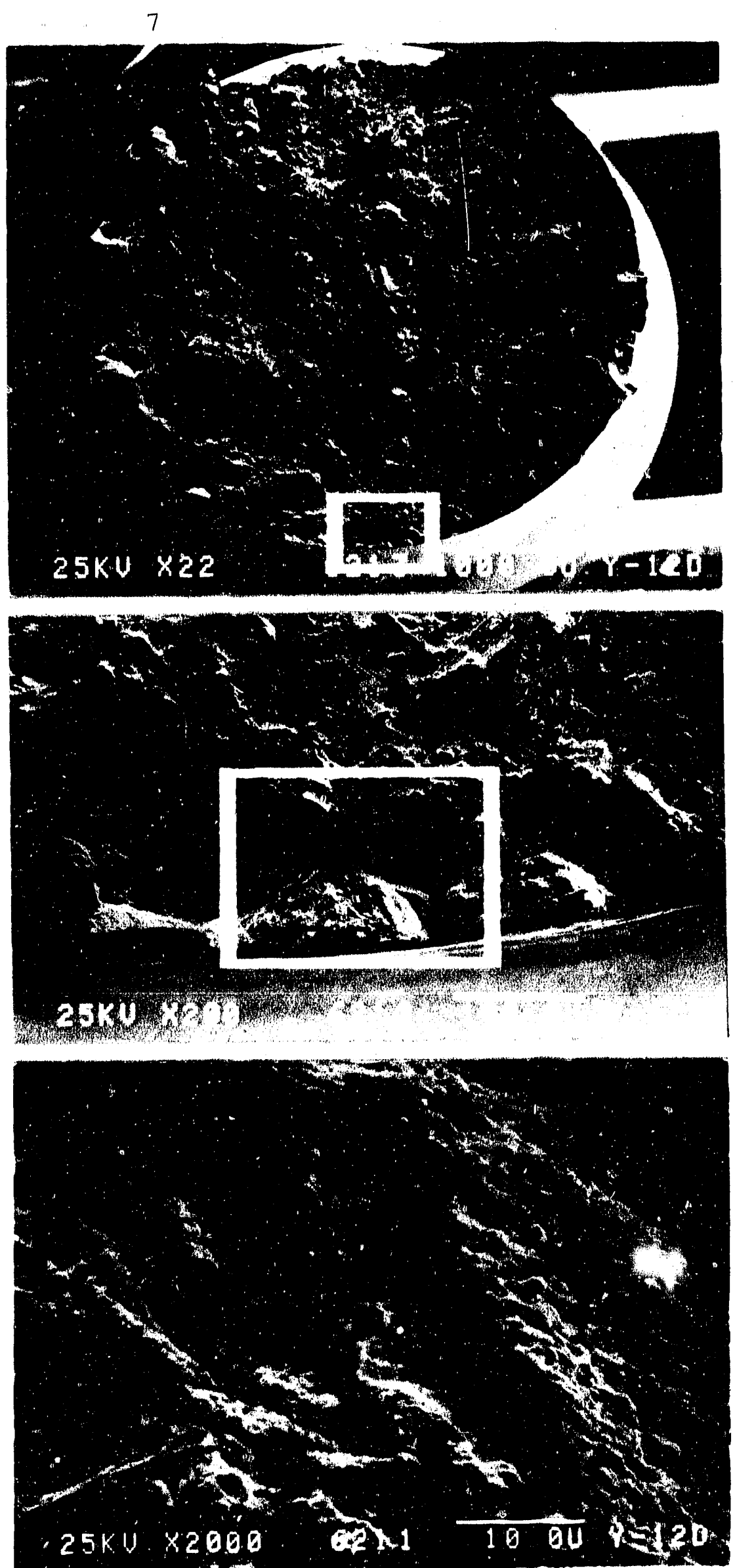

Fig. 1. Scanning electron microscope photos of tensile specimen fracture origin at inclusion cluster. 
preparation of six more tensile specimens from the same test component. The results of these specimens, which are presented in Table 4, are quite similar to the same erratic behavior observed in the sister test group. These results indicate that internal hydrogen, even at relatively low levels of $0.36 \mathrm{ppm}$, contribute strongly to the erratic ductile properties of U-0.8Ti tensile specimens tested at the current crosshead velocity of $0.15 \mathrm{in} . / \mathrm{min}$. These results are plotted in Fig. 2.

Another phenomenon observed in this study was the differences in fracture morphology associated with the fracture surfaces. For the low hydrogen specimens $(0.02 \mathrm{ppm})$, the failure mode was more ductile, especially at the faster strain rate. The fracture mode tended to become more quasi-cleavage or mixed for the hydrogenated specimens, and there was usually evidence of secondary cracking. These features are described in Table 5. Metallographic cross sections through one of the predominantly ductile or microvoid coalescence fractures revealed a transmartensitic crack path that propagated through the alpha prime martensitic platelets. Those fractures that exhibited a predominantly quasi-cleavage fracture mode indicate that cracking tends to occur along the martensitic platelets or alnng the interfaces between the martensitic platelets and the surrounding matrix. Microstructural photomicrographs depicting both fracture patterns are provided in Fig. 3.

Table 4. Mechanical properites of additional specimens

\begin{tabular}{ccccc}
\hline $\begin{array}{c}\text { Test } \\
\text { component }\end{array}$ & Section & $\begin{array}{c}\text { Ultimate tensile } \\
\text { strength (ksi) }\end{array}$ & $\begin{array}{c}\text { Yield strength } \\
(\mathrm{ksi})\end{array}$ & $\begin{array}{c}\text { Elongation } \\
(\%)\end{array}$ \\
\hline 1 & 3 & 221.0 & 140.5 & $14.1 a, b$ \\
& 221.3 & 139.2 & 18.0 \\
& 219.5 & 139.2 & $12.5 b$ \\
& 218.8 & 133.8 & 18.0 \\
& 220.8 & 130.9 & 14.1 \\
& 218.6 & 139.0 & $9.4 a, b$ \\
& $220.0+1.1$ & $137.1+3.5$ & $14.4+3.0$ \\
\hline
\end{tabular}

a Specimen broke outside middle half of gage marks.

$b$ Inclusion cluster at fracture origin. 


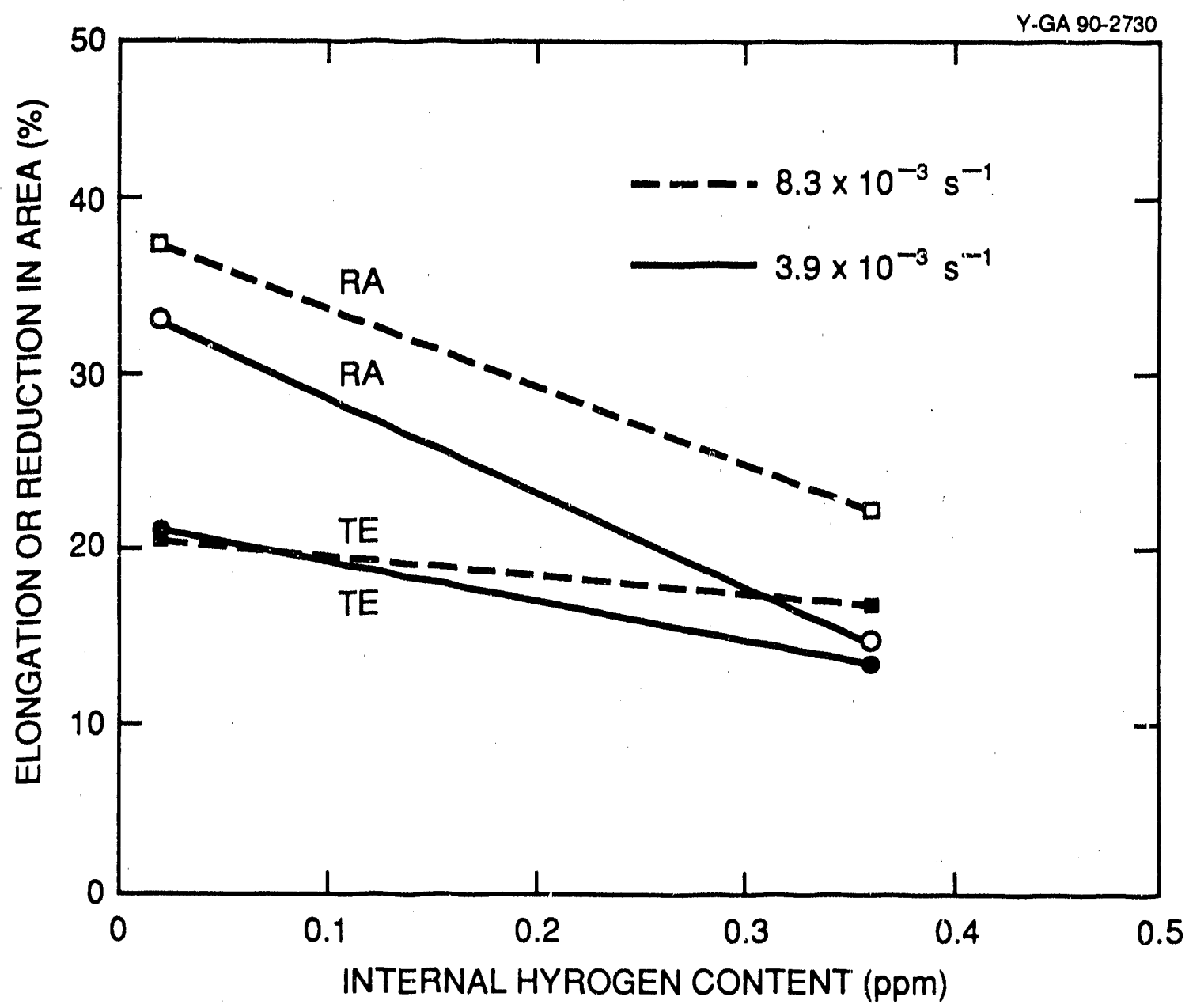

Fig. 2. Ductility versus hydrogen content for aged uranium- 0.8 titanium tested at two strain rates.

Table 5. Fracture morphologies associated with each test condition

\begin{tabular}{ccl}
\hline $\begin{array}{c}\text { Hydrogen content } \\
(\mathrm{ppm})\end{array}$ & $\begin{array}{c}\text { Strain rate } \\
\text { (in./in./s) }\end{array}$ & \multicolumn{1}{c}{ Failure mode } \\
\hline 0.02 & 0.0039 & Mixed, predominantly microvoid coalescence \\
0.02 & 0.0083 & $\begin{array}{l}\text { Microvoid coalescence } \\
\text { Mixed, predominantly quasi-cleavage with } \\
0.36\end{array}$ \\
0.0039 & $\begin{array}{l}\text { Mecondary cracking } \\
\text { sixed, predorninantly quasi-cleavage with }\end{array}$ \\
\hline
\end{tabular}




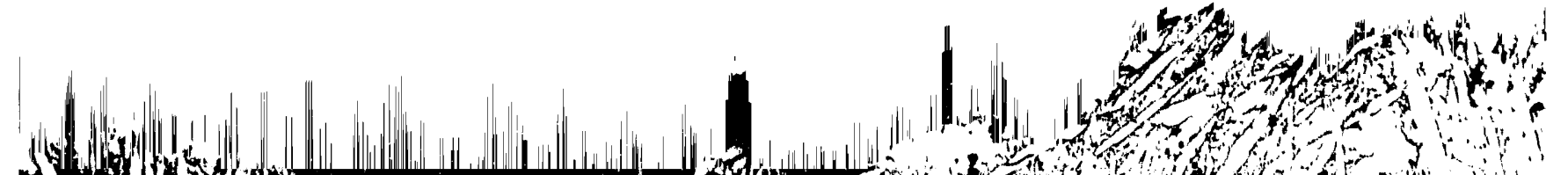
(1)
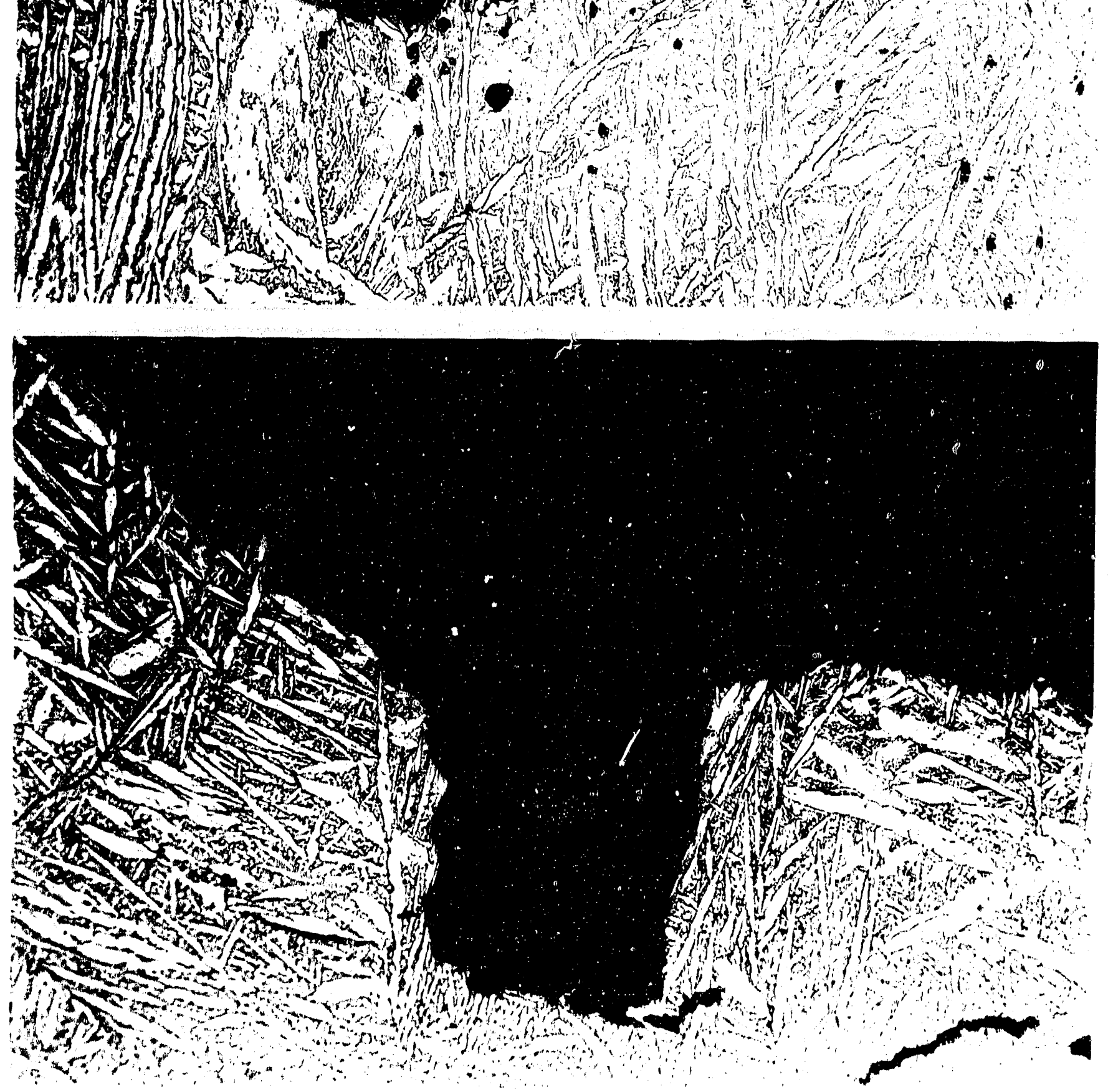

Figure 3. Fracture paths associated with predominantly ductile failure through martensitic platelets (above) and britte, mixed mode along martensitic platelets (below). Also, in bottom photograph note secondary cracking observed in higher hydrogen specimen. 


\section{DISCUSSION}

Internal hydrogen, even in relatively small bulk amounts of $0.36 \mathrm{ppm}$, can contribute significantly to erratic ductile properties is U-0.8Ti alloys tested at a crosshead velocity of $0.15 \mathrm{in} . / \mathrm{min}$. Increasing the speed to $0.32 \mathrm{in} . / \mathrm{min}$ improved the average elongation, but the higher average value was not statistically significant Reduction in area properties were significantly better at the faster strain rate. The preponderance of erratic ductile behavior observed in the higher hydrogen test group tested at the slower strain zate appears to be based on a strong correlation with inclusions. This phenorezon might be explained by the following theory: an inclusion cluster or notch serves an excellent crack nucleation site, especially in the U-Ti alloy, which is sensitive to hydrogen embrittlement. The application of a tensile load during testing causes the creation of a triaxial stress field in the vicinity of the defect and the migration of hydrogen atoms to the zone of stress intensity. A natural crack, with a crack tif much sharper than the blur ed tip of the inclusion cluster, nucleates resulting in a triaxial stress field of even greater intensity. More hydrogen atoms migrate to the triaxial stress zone and the region immediately preceding the crack tip becomes saturated or enhanced with hydrogen primarily in the for $\mathrm{m}$ of hydrides $\left(\mathrm{UH}_{3}\right)$, thereby causing localized embrittlement and a lowering of the threshold stress intensity for subsequent crack growth. This theoretical model is graphically illustrated in Fig. 4. The coucept of hydrogen migration to regions of concentrated stresses was originally proposed by Troiano and co-workers, ${ }^{4,5}$ but could not be demonstrated because of the tendency of hydrogen to redistribute when the load was removed. However, efforts to measure hydrogen redistribution in the titanium-31 vanadium (Ti-31V) alloy were successful under plain strain conditions using nuclear reaction analysis. $^{6}$ Robinson, et al, used tritium, which is the radioactive isotope of hydrogen that decays to helium, to demonstrate the concept of hydrogen isotope con entration enhancement at a blunt notch in the titanium-30 molybdenum (Ti-30Mo) alloy. ${ }^{7}$ The approximate size or width of the affected plastic zone at the crack tip can be calculated using the following formula:

$$
w=a\left(\sigma / \sigma_{y}\right)^{2}
$$

where

$$
\begin{aligned}
& w=\text { plastic zone size } \\
& a=\text { crack length } \\
& \sigma=\text { ultimate tensile stress, and } \\
& \sigma_{y}=\text { yield stress in tension. }
\end{aligned}
$$

For a crack length of 0.010 in., which is the size of some of the very large inclusion clusters, the plastic zone size is calculated as 0.025 in.

As the internal hydrogen content increased and/or the strain rate decreased, cracking tended to preferentially propagate along the martensitic platelet-matrix interface, perhaps because the interface is more heavily saturated with $\mathrm{UH}_{3}$. Brittle or quasi-cleavage type fractures have also been observed in tensile specimens with large inclusion clusters or notches, even when the internal hydrogen content was extremely low $(0.03 \mathrm{ppm})$ because of the high state of triaxial stresses created at the flaw. Another explanation that may be more applicable to inclusion clusters might be the interaction between hydrogen and trap sites as postul: ed 
(a) Uniaxial load ( $\sigma$ ) applied to tensile specimen with inclusion cluster (C) at surface. Triaxial stresses ( $T$ ) develop at tip of inclusion cluster as hydrogen $(\mathrm{H})$ migrates to stressed region (T).

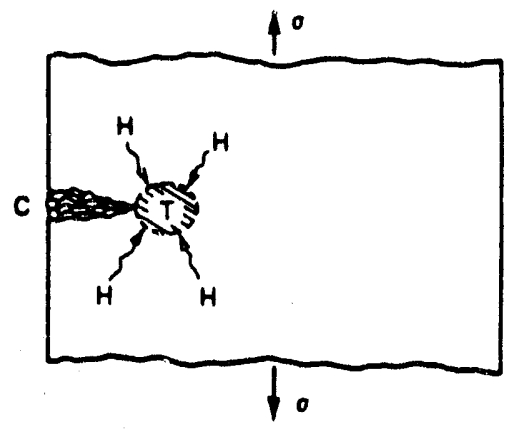

(b) Crack propagates into matrix as more hydrogen $(\mathrm{H})$ migrates to region of triaxial stresses (T) immediately in front of crack tip.

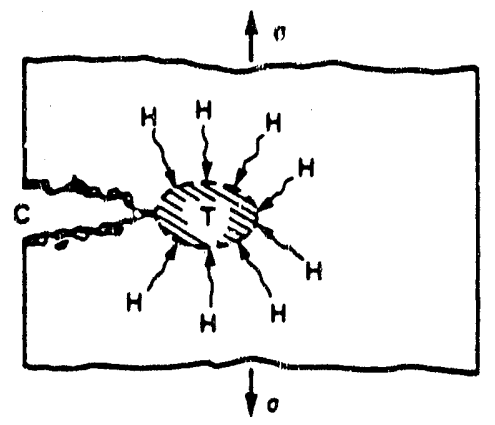

Fig. 4. Theoretical model of hydrogen-assisited crack originating at inclusion cluster.

by Pressouyre, et al. ${ }^{9}$ A basic assumption of the trap theory is that a crack will initiate on a given defect if the quantity of trapped hydrogen exceeds a critical concentration. The critical concentration of a defect depends on a number of variables including the shape of the defect, grain boundary coherency, applied stress, temperature, and adsorbed impurities at the interface of the defect/matrix. Indeed, the correlation of inclusion clusters and erratic ductile properties was much more pronounced in the higher hydrogen specimens but only at the slower strain rate.

In conclusion, this study has demonstrated that for U-0.8Ti alloys with very low internal hydrogen, i.e., less than $0.10 \mathrm{ppm}$, that are tested in a controlled environment containing less than $10 \%$ relative humidity, increasing the crosshead velocity would not be of significaist Lenefit to current mechanical properties requirements. However, as the internal hydrogen increases, the advantages in increasing the crosshead velocity to $0.32 \mathrm{in} . / \mathrm{min}$ become clear. Although not statistically significant, testing at the faster speed appears to mitigate the deleterious effects of material defects, thereby resulting in greater total elongation values with less variance. 


\section{FUTURE WORK}

Another test piece will be sectioned from the component with $0.36 \mathrm{ppm}$ hydrogen; and a single, localized notch will be machined into the center of the gage length of each tensile specimen for testing at the current strain rate.

\section{ACKNOWLEDGEMENTS}

The author wishes to thank M. J. Marsicek and his staff for performing mechanical testing, W. L. Bolinger for his examinati a of the tensile fractures using the SEM, and S. E. Stinnette for performing statistical analyses of the data. Also, a special thanks to K. H. Eckelmeyer, B. C. Odegard, J. J. Dillon, G. M. Ludtka, and G. L. Powell for their input and meaningful technical discussions. 


\section{REFERENCES}

1. American Society for Testing and Materials, Section 3, Metals Test Methods and Analytical Procedures, Vol. 03.01, 1986, 1916 Race Street, Philadelphia, PA 19103, pp. 124-145.

2. Jackson, R. J., Acquired Hydrogen Embrittlement During Tensile Loading on the Uranium-3/4 Weight Percent Titanium Alloy, RFP-3955, November 24, 1986, Rockwell International. (U)

3. Powell, G. L., "Overview of Hydrogen Embrittlement of Uranium and Uranium Alloys," Union Carbide Corp., Nuclear Div., Metallurgical Technology of Uranium and Uranium Alloys, pp. 877-899, American Society for Metals, c 1982. (U)

4. Steigerwald, E. A., Schaller, F. W., and Troiano, A. R., Transactions TMS-AIME, 214, p. $1048,1959$.

5. Troiano, A. R., Transactions .ASM, p. 54, 1960.

6. Schulte, R. L., Adler, P. N., and Patcn, N. E., Hydrogen Effects in Metals, Proceedings of a Conference, TMS-AIME, pp. 177-186, Warrendaie, PA, 1981.

7. Robinson, S. L., Moody, N. R., Costa, J. C., Pontau, A. E., and Gerberich, W. W., "Hydrogen Isotope Concentration Enhancements at a Blunt Notch," Scripta Metallurgica, Vol. 24, pp. 111-116, 1990.

8. "Microscopic and Macroscopic Fundamentals," Fracture, An Advanced Treatise, Vol. 1, Academic Press, Inc., 111 Fifth Avenue, New York, NY, 1003, pp. 498-502, 1968.

9. Pressouyre, G. M., Fidelle, J. P., and Arnould Laurent, R., Trap Theory of Hydrogen Embrittlement: Experimental Investigations, Hydrogen Effects in Metals, pp. 27-36, Warrendale, PA, Metallurgical Society of AIME, c1981. 

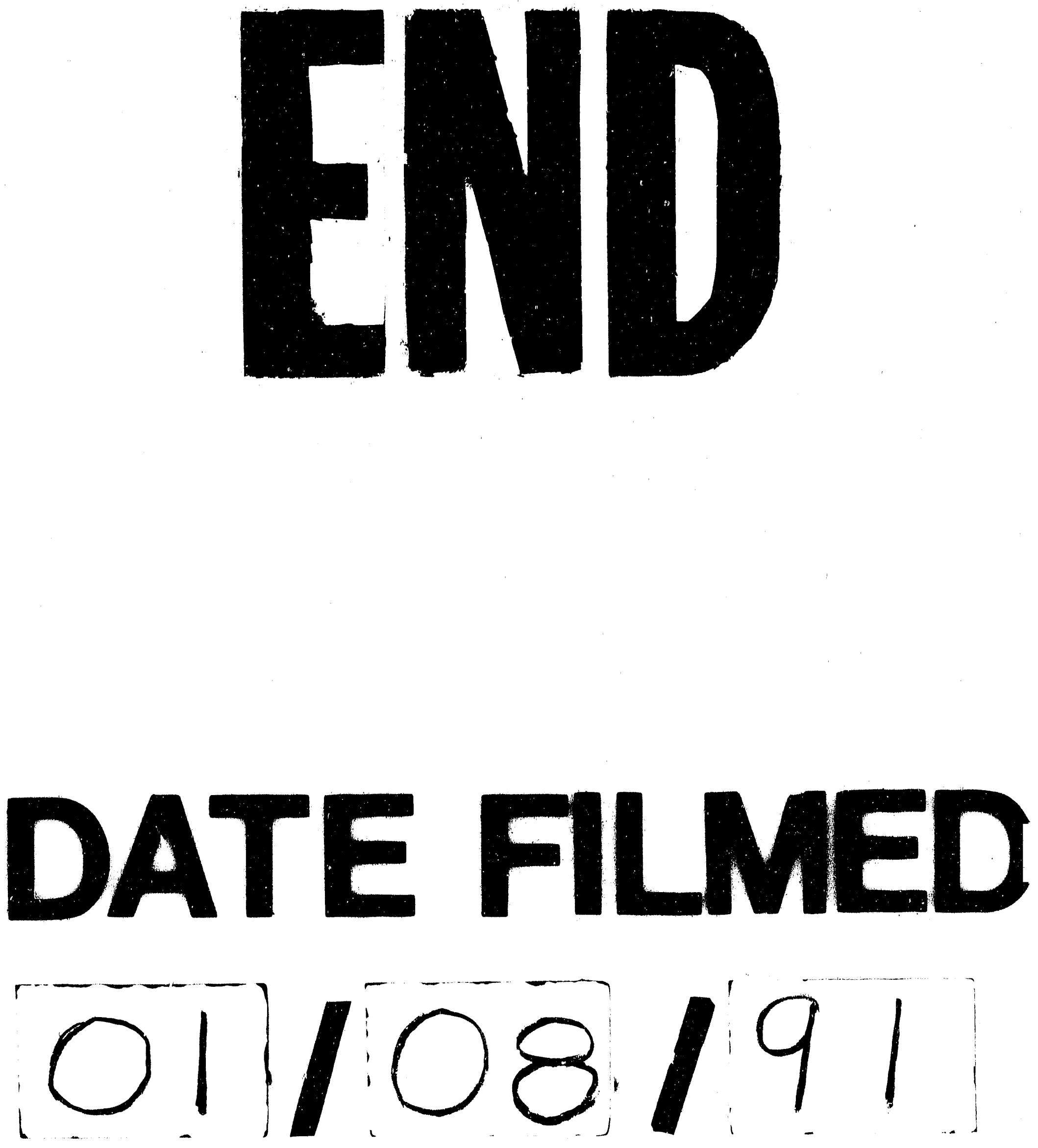
